\title{
The Effects of Orofacial Myofunctional Training on the Changes of Lip and Tongue Strength in Elderly People
}

\author{
Seol-Hee $\mathrm{Kim}^{\dagger}$, Min-Ju Kim, Seung-Hyun Lee, Bo-Wha Choi, and Yae-Jee Heo \\ Department of Dental Hygiene, College of Medical Science, Konyang University, Daejeon 35365, Korea
}

\begin{abstract}
Background: Increasing age and loss of teeth weaken oral muscle strength. This study aimed to investigate the positive effects of orofacial myofunctional training on elderly people.

Methods: Thirty six elderly individuals in a welfare center and a senior citizen center were included in this study. A survey regarding lip and tongue strength suvsequent to orofacial myofunctional training and oral health-related quality of life was conducted from April to June, 2019. Data were analyzed using PASW statistics ver. 18.0.

Results: The experimental group, showed an increase in lip strength (from 9.79 to 10.31) and tongue strength (from 41.26 to 43.97) after orofacial myofunctional training. The perception of oral health-relatedquality of life was enhanced (from 2.26 to 2.07). In particular, the frequency of dry cough for food removal while swallowing decresed due to an incresed in the secretion of saliva $(p<0.05)$. Correlation analysis showed that the number of functional teeth was positively related to oral health-related quality of life.

Conclusion: Orofacial myofunctional training for improving lip and tongue strength is effective in the elderly. In older societies, oral strength should be maintained to improve oral health-related quality of life. It also suggests the interest of oral health workers and applying orofacial myofunctional training programs.
\end{abstract}

Key Words: Elderly, Lip, Myofunctional therapy, Tongue, Tooth, Quality of life

\section{Introduction}

The average life expectancy of elderly people is 82.4 years and the healthy life years is 64.9 years, which means that people suffer from diseases for an average duration of 17.5 years $^{1)}$. Therefore the importance of healthcare in an aged society is currently being emphasized. An adequate supply of nutrients is essential to sustain good health. Therefore it is necessary to maintain oral muscle functions such as chewing and swallowing through proper care of teeth, gums, and oral myofunctions ${ }^{2)}$. However, elderly people face increased oral health risks due to a combination of factors including periodontal diseases caused by accumulated dental caries, diminished oralhealthcare ability, and xerostomia caused by systemic diseases and medications ${ }^{3)}$.

Due to oral diseases that caccumulate with increasing age, the number of remaining teeth in elderly people decreases from an average of 22.5 during the ages of $60 \sim$ 69 years to 15.4 at the age of $\geq 70$ years ${ }^{4}$. Consequently, the percentage of people with chewing difficulty increases approximately 5 -fold, from $8.1 \%$ in young people aged $20 \sim$ 39 years to $39.5 \%$ in elderly people aged $\geq 65$ years ${ }^{5}$. Moreover, tooth loss causes a decline in oral muscle functions. The group with $<15$ teeth showed weaker tongue and lip muscle strength than the group with $\geq 15$ teeth, indicating that tooth loss results in a decrease in oral muscle strength ${ }^{6}$.

Oral muscles, which consist of masticatory, tongue, and lip muscles, play an important role in oral functions such 
as chewing, swallowing, and speech. The functions of the tongue muscle include moving food to locations between the teeth where they could be chewed better and pushing food to the pharynx during swallowing ${ }^{7)}$. It also supports dentures to prevent them from falling out and has an influence on increasing satisfaction in life through its taste function $^{8)}$. Decreased tongue muscle strength could cause symptoms of dysphagia such as not being able to swallow food normally and coughing during swallowing. Approximately $33.7 \%$ of elderly people experience dysphagia due to decreased muscle tone and spasm delay ${ }^{9)}$, which could lead to malnutrition, dehydration, problems taking medicine, and even death due to aspiration pneumonia caused by food entering the airway ${ }^{10)}$.

The lip muscles prevent food from spilling out through the oral angles when eating. Together with the tongue and buccinator muscles, it also moves food around for chewing. Decreased lip muscle strength could cause food to spill out, which could have a negative effect on the oral health-related quality of life (OHR-QoL) as the concerned person avoids having meals with others ${ }^{11)}$.

Edentulous people have thinner and weaker masticatory muscles than dentulous people ${ }^{12)}$. Consequently, a vicious cycle appears whereby avoiding hard and chewy foods causes malnutrition and the oral muscle strength of malnourished elderly people decreases further ${ }^{13,14)}$. Moreover, decreased oral muscle strength could reduce mouth opening capacity and tongue mobility ${ }^{7)}$ while also affecting occlusal force $^{15)}$. Therefore, elderly people need oral muscle strengthening training for maintaining dental health and oral muscle functions.

In other countries, tongue muscle strengthening training ${ }^{16)}$, lip muscle strengthening training ${ }^{17)}$, and oral muscle training $^{18)}$ are applied to strengthen oral muscle functions. Based on these, oral muscle training using head and neck stretching, vocal exercise, and tongue calisthenics are currently being applied in Korea. However, most of the studies relate to the field of occupational therapy and focus primarily on the effects of breathing and oral exercise training on patients with diseases such as cerebral palsy or stroke $^{19)}$. In the field of dental hygiene, studies have been conducted on improving saliva secretion, xerostomia, and halitosis using oral calisthenics ${ }^{20)}$. However, because the studies investigate the subjective perception of the participants, there are limitations on making comparisons to studies from outside of Korea this indicates a need to enhance the assessing tools. Moreover, studies on improvement of swallowing functions, which is the biggest issue related to oral muscle function in elderly people, are lacking.

Accordingly, the present study assessed the oral muscle functions of elderly people and applied tongue muscle strengthening training for improving swallowing and lip muscle-strength training for reducing food spill and also analyzed the effects of such training on the strengthening of oral muscles. The objective of the study was to use the findings to enhance the awareness of oral healthcare workers regarding oral muscle training and to suggest the need fordevelopment and application of oral muscle training programs.

\section{Materials and Methods}

\section{Study population}

The study population consisted of elderly people aged $\geq 65$ years who use a welfare center and/or two senior citizen centers in apartment complexes located in Daejeon metropolitan city. The study was conducted between April and June 2019 after an explanation on the objectives of the study and the ethical considerations was provided to the candidates and a written consent for participation was obtained. The study population included dentulous and edentulous people at the time of the oral examination, while those who could not understand the examination process or refused to participate in the examination were excluded from the study. The sample size calculated using $\mathrm{G}^{*}$ power program ver. 3.1.9.2 indicated that 21 participants were required for each group. Accordingly, the study was conducted with 25 participants each in the experimental and control groups. Excluding those who withdrew their consent to participate and underperformed during the study, 15 participants from the experimental (oral muscle training) group and 21 participants from the control group were included in the final analysis. 


\section{Methods}

For the oral muscle training, oral function improvement exercises from Japan and oral calisthenics from Korea were referenced $^{17,18,20,21)}$, and muscle function strengthening training was conducted after upgrading some methods, as shown in Fig. 1. The participants in the experimental group performed oral muscle training once a week (50 minutes every Thursday) for eight weeks at the welfare center, and were subsequently instructed to perform self-training. Assessments were made both before and after the oral muscle training. The control group was also assessed at the same time. Assessment items included oral examination, oral muscle function test, perception of OHR-QoL, and appraisal of oral muscle training.

\section{1) Oral muscle training}

Oral muscle training consisted of basic exercise, followed by oral muscle stretching, tongue, lip, and masticatory muscle exercise, and massage. The difference, when compared with conventional oral calisthenics, was the use of a tongue bulb (IOPI Medical, Redmond, WA, USA) for tongue and lip muscle strengthening training. The purpose of this was to have the participants numerically verify pressure change during personal training for tongue muscle strengthening, and to enhance the effects of oral muscle training through self-performance by providing the tongue bulb and educating the participants on how to use the bulb.

\section{2) Oral muscle strength test}

Oral muscle strength was measured with the participant seated in a comfortable position while facing forward. In between measurements, a questionnaire survey on OHR-
QoL was conducted, allowing at least one minute of rest. For each measured item, the mean value of three measurements was used in the analysis. For lip muscle strength, the Lip de $\mathrm{Cum}^{\circledR}$ (Cosmo Instruments Co., Ltd., Tokyo, Japan) was used to place a lip holder connected to sensors on the upper and lower lips, and the maximum force applied for three seconds in the vertical direction was measured. To measure tongue muscle strength, IOPI ${ }^{\mathbb{R}}$ (IOPI Medical) was connected to the tongue bulb to measure the maximum pressure of the tongue pressing on the palatal region.

\section{3) Survey of oral health-related quality of life}

Patients were requesteasked to answer a retrospective survey based on their experiences of the past 1 year; the survey included 10 items, of which mprisedseven that focussed on the OHR-QoL assessed using Oral Health Impact Profile-14 $4^{22}$, (functional limitations, and physical pain selective food consumption, discomfort during food intake, difficulties in pronunciation, discomfort while swallowing, taste problems, jaw pain, and aesthetic satisfaction) and three items that focused on the swallowing ability, which were assessed using Swallowing Quality of Life Questionnaire ${ }^{23)}$ (bolus flow, food stagnation due to dryness in the mouth while swallowing, coughing to remove bolus while swallowing). Responses were recorded using a five-point Likert scale from 0 indicating "not at all" to 5 indicating "very frequently" with a higher score suggestings a more negative perception.

\section{Analysis}

Participants' general characteristics, oral muscle strength, and perceived OHR-QoL were analyzed with descriptive

\begin{tabular}{|c|c|c|}
\hline $\begin{array}{l}\text { Step 1. Basic exercise } \\
\text { Deep breath } \\
\text { Neck/shoulder exercise }\end{array}$ & $\begin{array}{l}\text { Step 2. Oral muscle stretch } \\
\text { "A, E, I, O, U" highest limit }\end{array}$ & $\begin{array}{l}\text { Step 3. Tongue exercise } 1 \\
\text { "Pa Ta Ka Ra" } \\
\text { "tick-tock" }\end{array}$ \\
\hline $\begin{array}{l}\text { Step 4. Tongue exercise } 2 \\
\text { Press - tongue bulb } \\
\text { Swallow exercise }\end{array}$ & $\begin{array}{l}\text { Step } 5 \text {. Tongue exercise } 3 \\
\text { Touch - vestibulum oris }\end{array}$ & $\begin{array}{l}\text { Step } 6 \text {. Lip exercise } \\
\text { Keep water in mouth+step } 5 \\
\text { Keep lip when pull tongue bulb }\end{array}$ \\
\hline $\begin{array}{l}\text { Step 7. Lip, buccal exercise } \\
\text { Put air in a lip \& cheek } \\
\text { Smile, U motion - repeat }\end{array}$ & $\begin{array}{l}\text { Step 8. Masseeter muscle } \\
\text { Open mouth - resistance } \\
\text { Close mouth - resistance }\end{array}$ & $\begin{array}{l}\text { Step 9. Massage } \\
\text { Masseeter muscle } \\
\text { Salivary gland }\end{array}$ \\
\hline
\end{tabular}

Fig. 1. Oral muscle training. 
statistics. Differences in general characteristics, oral muscle strength, and perceived OHR-QoL were analyzed with Mann-Whitney U-test, paired sample Wilcoxon signed-rank test, and Spearman correlation. The statistical significance level was set to 0.05. Analyses were performed using the PASW Statistics ver. 18.0 (IBM Corp., Armonk, NY, USA) software.

\section{Results}

\section{Participants' general characteristics}

There were 15 participants in the experimental group with a mean age of 77 years and 21 in the control group with a mean age of 79 years ( $p>0.05)$. Of the participants, $66.70 \%$ in the experimental group and $47.60 \%$ in the control group had perceived experience dry mouth symptoms; the number of functional teeth was 23.60 in the experimental group and 18.95 in the control group $(\mathrm{p}>$ 0.05). Lip strength was 9.79 in the experimental group and 8.42 in the control group while tongue strength was 41.26 in the experiment group and 41.08 in the control group. The perceived OHR-QoL was 2.26 in the experimental group and 2.63 in the control group ( $\mathrm{p}>0.05)$ (Table 1).

Table 1. Participants' General Characteristics

\begin{tabular}{lccc}
\hline \multicolumn{1}{c}{ Variable } & $\begin{array}{c}\text { Experimental } \\
\text { group } \\
(\mathrm{n}=15)\end{array}$ & $\begin{array}{c}\text { Control } \\
\text { group } \\
(\mathrm{n}=21)\end{array}$ & p-value \\
\hline Gender & & & 0.573 \\
Male & $4(26.70)$ & $4(19.00)$ & \\
Female & $11(73.30)$ & $17(81.00)$ & \\
Age (y) & $77.06 \pm 4.52$ & $79.14 \pm 4.49$ & 0.182 \\
Dry mouth & & & 0.214 \\
Yes & $10(66.70)$ & $10(47.60)$ & \\
$\quad$ No & $5(33.30)$ & $11(52.40)$ & \\
Smoking & $4(26.70)$ & $1(4.8)$ & 0.084 \\
$\quad$ Yes & $11(73.30)$ & $20(95.20)$ & \\
$\quad$ No & $0.43 \pm 0.77$ & $0.33 \pm 1.52$ & 0.818 \\
Drinking (wk) & $23.60 \pm 6.16$ & $18.95 \pm 7.76$ & 0.63 \\
Number of functional teeth & $9.79 \pm 1.85$ & $8.42 \pm 2.43$ & 0.77 \\
Lip strength & $41.26 \pm 6.00$ & $41.08 \pm 10.11$ & 0.72 \\
Tongue strength & $2.26 \pm 0.59$ & $2.63 \pm 0.64$ & 0.086 \\
OHR-QoL & & & \\
\hline
\end{tabular}

Values are presented as $\mathrm{n}(\%)$ or mean \pm standard deviation. OHR-QoL: oral health-related quality of life.

\section{Changes in oral muscle strength after oral muscle training}

The experimental group showed an increase in lip strength from 9.79 before oral muscle training to 10.31 after training and an increase in tongue strength from 41.26 to 43.97. OHR-QoL decreased from 2.26 to 2.07, showing the alleviation of negative influence $(p<0.05)$. The control group showed an increase in lip strength from 8.42 to 8.56 and tongue strength from 41.08 to 42.19 after 8 weeks of training, and their OHR-QoL increased from 2.63 to 2.71 ( $\mathrm{p}>0.05$ ) (Table 2 ).

\section{Perception of oral health-related quality of life before and after oral muscle training in the experimental group}

Analysis of OHR-QoL perception before and after oral muscle training in the experimental group showed that the frequency of dry coughs for removing food during swallowing decreased from 3.13 to 2.40 , which is a statistically significant decrease $(\mathrm{p}<0.05)$. Moreover, the score denoting the feeling of food getting stuck in the mouth and throat changed from 2.27 to 1.93 , while the score implying food spilling out while eating decreased from 1.40 to 1.13 , but the differences were not statistically significant $(\mathrm{p}>0.05)$ (Table 3$)$.

Table 2. Changes in Oral Muscle Strength after Oral Muscle Training

\begin{tabular}{lcccc}
\hline & $\begin{array}{c}\text { Experimental } \\
\text { group } \\
(\mathrm{n}=15)\end{array}$ & p-value & $\begin{array}{c}\text { Control } \\
\text { group } \\
(\mathrm{n}=21)\end{array}$ & p-value \\
\hline Lip strength & & 0.027 & & 0.684 \\
$\quad$ Pre & $9.79 \pm 1.85$ & & $8.42 \pm 2.43$ & \\
$\quad$ Post & $10.31 \pm 1.78$ & & $8.56 \pm 2.44$ & \\
Tongue strength & & 0.040 & & 0.642 \\
$\quad$ Pre & $41.26 \pm 6.00$ & & $41.08 \pm 10.11$ & \\
$\quad$ Post & $43.97 \pm 5.63$ & & $42.19 \pm 9.79$ & \\
OHR-QoL & & 0.011 & & 0.163 \\
$\quad$ Pre & $2.26 \pm 0.59$ & & $2.63 \pm 0.64$ & \\
$\quad$ Post & $2.07 \pm 0.51$ & & $2.71 \pm 0.55$ & \\
\hline
\end{tabular}

Values are presented as mean \pm standard deviation. OHR-QoL: oral health-related quality of life. 
Table 3. Perception of OHR-QoL before and after Oral Muscle Training in the Experimental Group

\begin{tabular}{|c|c|c|c|c|}
\hline Variable & Pre & Post & Post-pre & p-value \\
\hline OHR-QoL & $2.22 \pm 0.58$ & $2.07 \pm 0.51$ & -0.15 & 0.020 \\
\hline \multicolumn{5}{|l|}{ Mastication } \\
\hline Uncomfortable to eat any foods (food selection) & $2.14 \pm 1.51$ & $2.00 \pm 1.30$ & -0.14 & 0.336 \\
\hline Food impaction & $2.87 \pm 1.50$ & $3.07 \pm 1.58$ & 0.20 & 0.189 \\
\hline Painful aching joint & $1.13 \pm 0.35$ & $1.20 \pm 0.56$ & 0.07 & 0.334 \\
\hline \multicolumn{5}{|l|}{ Lip strength } \\
\hline Limplying food spilling out while eating & $1.40 \pm 0.35$ & $1.13 \pm 0.35$ & -0.27 & 0.104 \\
\hline Trouble pronouncing any words & $1.60 \pm 0.98$ & $1.53 \pm 0.91$ & -0.07 & 0.334 \\
\hline \multicolumn{5}{|l|}{ Swollowing } \\
\hline Stuck in the mouth and throat & $2.27 \pm 1.38$ & $1.93 \pm 0.79$ & -0.34 & 0.096 \\
\hline Dry coughs for removing food during swallowing & $3.13 \pm 1.35$ & $2.40 \pm 0.91$ & -0.73 & 0.003 \\
\hline Swallowing trouble & $2.00 \pm 1.06$ & $1.93 \pm 1.03$ & -0.07 & 0.334 \\
\hline \multicolumn{5}{|l|}{ Oral function } \\
\hline Esthetic satisfaction & $3.47 \pm 1.06$ & $3.13 \pm 0.99$ & -0.34 & 0.136 \\
\hline Problem of taste & $2.20 \pm 1.37$ & $2.07 \pm 1.22$ & -0.13 & 0.164 \\
\hline Pain of tooth $\&$ perio & $2.60 \pm 1.12$ & $2.47 \pm 1.06$ & -0.13 & 0.164 \\
\hline
\end{tabular}

Values are presented as mean \pm standard deviation or number only.

OHR-QoL: oral health-related quality of life.

Table 4. Correlation Analysis on the Number of Functional Teeth, Lip Muscle Strength, Tongue Muscle Strength, and OHR-QoL

\begin{tabular}{lcccc}
\hline \multicolumn{1}{c}{ Variable } & Number of functional teeth & Lip strength & Tongue strength & OHR-QoL \\
\hline Number of functional teeth & 1 & & & \\
Lip strength & 0.002 & 1 & 1 & \\
Tongue strength & 0.092 & $0.344^{*}$ & 0.046 & 0.170 \\
OHR-QoL & $-0.389^{*}$ & 0.046 & 1 \\
\hline
\end{tabular}

OHR-QoL: oral health-related quality of life. ${ }^{*} \mathrm{p}<0.05$.

4. Correlation analysis on the number of functional teeth, lip strength, tongue muscle strength, and oral health-related quality of life

Results of correlation analysis on the number of functional teeth, lip strength, tongue strength, and OHRQoL, show a correlation between the number of functional teeth and OHR-QoL $(r=-0.389, \mathrm{p}<0.05)$, with a higher number of functional teeth relating to a more positive perception of OHR-QoL. Moreover, a statistically significant positive correlation was found between lip and tongue strength $(\mathrm{r}=0.344, \mathrm{p}<0.05)$ (Table 4$)$.

\section{Discussion}

The mean age of elderly people who participated in the present study was 78 years, while the mean number of teeth was 20.5. In the Korea National Health and Nutrition Examination Survey, the mean number of remaining natural teeth among elderly people aged $\geq 70$ years was 15.8 , which indicates that the mean number of teeth was higher among the participants of the present study ${ }^{24}$. Perception of xerostomia was $55 \%$, meaning more than half of the study population experienced discomfort due to xerostomia. The number of elderly patients visiting dentists is expected to increase due to the increased prevalence of dry oral mucosa, loss of elasticity, pain, hypogeusia, periodontal disease, oral candidiasis, and intraoral infection, such as sialadenitis ${ }^{20)}$. Therefore, preventive measures are needed to resolve oral health issuesincluding xerostomia in elderly people.

In studies that applied oral calisthenics in elderly 
people, oral calisthenics were recommended for improving xerostomia in elderly people based on the results showing significant decrease in xerostomia symptoms and discomfort $^{25)}$. Moreover, oral calisthenics can reduce food spilling, improve swallowing function and chewing function weakened by loss of teeth, and reduce masticatory muscle atrophy $^{26)}$.

Approximately $33.7 \%$ of elderly people experience dysphagia due to decreased muscle tone and spasm delay ${ }^{9)}$. Which could lead to malnutrition through a negative impact on dietary behavior and nutritional intake ${ }^{26)}$. Consequently, it can also cause negative outcomes with respect to systemic health, and thus awareness of the importance of maintaining muscle functions is essential.

Based on the study that reported tongue pressure exercise for improving eating and swallowing impairment can contribute to enhancing the recovery of muscle strength, the present study focused on improving oral muscle issues related to eating in elderly people and applied oral muscle training using a tongue bulb for strengthening lip and tongue muscles as a modified form of conventional oral calisthenics. Our results indicate that the experimental group had a significant improvement (after oral muscle training) in lip muscle strength (9.79 to 10.31) and tongue muscle strength (41.25 to 43.97 ), while the negative effect on OHR-QoL was reduced (2.26 to 2.07). It is believed that in a study by $\mathrm{Kim}$ and $\mathrm{Ma}^{19}$, there was effective application from biofeedback as the participants verified changes in IOPI values during tongue muscle strengthening training, which encouraged active participation.

A similar study by Kim et al. ${ }^{27)}$ also reported an increase in lip muscle strength and a significant increase in the degree of oral wetness, occlusal force, and swallowing ability after oral calisthenics, thereby suggesting recovery not only in oral muscle strength but also in xerostomia and chewing and swallowing functions.

In the analysis of perception of OHR-QoL before and after oral muscle training in the experimental group, the results showed the most improvement in frequency of dry coughs for removing food during swallowing $(3.13,2.40)$, while the feeling of food getting stuck in the mouth and throat $(2.27,1.93)$ and negative perception about food spilling out while eating $(1.40,1.13)$ also improved.
OHR-QoL in elderly people included not only functional aspects but psychological aspects as well. Delayed eating due to chewing difficulties and food spilling out of the mouth causes stress and cimpels people to avoid eating meals with others. A decline in oral functions such as chewing and swallowing, also causes nutritional disorders and poor health due to insufficient food intake ${ }^{28-30)}$, and thus, management measures for alleviating such problems are essential in elderly people.

It was confirmed that such changes appeared in the results because the participants were aware of swallowing difficulties during the study and were concerned that such difficulties could be exacerbated with aging, and consequently, they put forth the effort in recognition of the fact that swallowing and other oral functions could be improved through oral muscle training. Therefore, an increase in awareness regarding the importance of maintaining oral functions and oral muscles through oral muscle training is essential in oral healthcare education for elderly people ${ }^{30}$. Currently, the field of occupational therapy includes treatment for dysphagia. Since chewing and swallowing are major oral functions, the field of dental hygiene should also take note of these issues it is necessary to include these aspects in college education. Moreover activation multidisciplinary and convergence studies and work performance for supporting healthy life in aging society are needed, regardless of the field.

Aging itself leads to loss of muscle strength, which could affect oral muscles and cause changes in swallowing function. When problems occur with the ability to control the oral phase of swallowing, stagnation of food, increased food residue due to decreased swallowing frequency, and delayed relaxation of the upper esophageal sphincter could cause apnea while swallowing, which in turn could increase the risk of aspiration pneumonia, which could be life-threatening ${ }^{24,25)}$. Swallowing takes place through a broad range of sensory-motor and neural interactions. Muscle and nerve damage could be redued by swallowing rehabilitation, which requires repeated exercise ${ }^{30,31)}$. In Japan, an oral function improvement program for oral health promotion reported that oral calisthenics program improved the oral health of elderly people and that it was especially effective in the elderly in aged and super-aged 
societies. It was also reported that such exercises had no adverse effects and that elderly people could continue to use such exercises without any economic burden or time and space constraints ${ }^{19,32,33)}$.

The present study was meaningful in that it promoted strengthening of lip and tongue muscles for improving swallowing functions through generic oral calisthenics. However, there are limitations in generalizing the findings since the study population included a small number of participants from a single region; the results were measured after one training session per week, and the results were derived from a short-term training program. Therefore, additional studies with more diverse study populations and longer study periods are required. Moreover, since awareness about oral muscle training is lacking in Korea, education and development of programs for maintaining and enhancing oral muscle functions are needed. Furthermore, the field of dental hygiene should build professional competency through convergence education and studies on elderly people there is also a need to publicize prevention programs for broader oral health promotion.

\section{Notes}

\section{Conflict of interest}

No potential conflict of interest relevant to this article was reported.

\section{Ethical approval}

This research was approved by the bioethics committee of Konyang University (KYU-2019-203-01).

\section{ORCID}

Seol-Hee Kim, https://orcid.org/0000-0003-1996-1306

Min-Ju Kim, https://orcid.org/0000-0002-0228-8197

Seung-Hyun Lee, https://orcid.org/0000-0001-6787-7243

Bo-Wha Choi, https://orcid.org/0000-0002-6902-2086

Yae-Jee Heo, https://orcid.org/0000-0003-3240-4280

\section{Acknowledgements}

This work was supported by the National Research Foundation of Korea (NRF) grant funded by the Korea government (MSIT) (NRF-2017R1C1B5017668).

\section{References}

1. Statistics Korea: Expected life and health life trend analysis results. Life table national approval statistics (No. 101035). Retrieved 2019 July 29, from http://www.index.go.kr/potal/ main/EachDtlPageDetail.do?idx_cd=2758(2018, Dec 16).

2. Kim SH: Effects of nutrient intake on oral health and chewing difficulty by age group. J Korea Acad-Ind Cooper Soc 19: 202-209, 2018. https://doi.org/10.5762/KAIS.2018.19.2.202

3. Ahluwalia KP, Cheng B, Josephs PK, Lalla E, Lamster IB: Oral disease experience of older adults seeking oral health services. Gerodontology 27: 96-103, 2010. https://doi.org/10.1111/j.1741-2358.2009.00311.x

4. Kim JS, Kim SY, Jun EJ, Jeong SH, Kim JB: The number of existing permanent teeth and the denture status of elderly adults aged 65 years and above living in metropolitan cities using data from the Korean National Health and Nutrition Examination Survey. J Korean Soc Dent Hyg 18: 921-932, 2018. https://doi.org/10.13065/jksdh.20180079

5. Statistics Korea: Korea Health Statistics: Korea National Health and Nutrition Examination Survey (KNHANES VI-3). Korea Center for Disease Control \& Prevention, Sejong, pp.1-503, 2015.

6. Kim SH: Analysis of correlation among oral environment, oral myofunction, and oral microorganisms. J Dent Hyg Sci 19: 96-106, 2019. https://doi.org/10.17135/jdhs.2019.19.2.96

7. Machida N, Tohara H, Hara K, et al.: Effects of aging and sarcopenia on tongue pressure and jaw-opening force. Geriatr Gerontol Int 17: 295-301, 2017. https://doi.org/10.1111/ggi.12715

8. Koshino H, Hirai T, Ishijima T, Ikeda Y: Tongue motor skills and masticatory performance in adult dentates, elderly dentates, and complete denture wearers. J Prosthet Dent 77: 147-152, 1997. https://doi.org/10.1016/S0022-3913(97)70228-2

9. Holland G, Jayasekeran V, Pendleton N, Horan M, Jones M, Hamdy S: Prevalence and symptom profiling of oropharyngeal dysphagia in a community dwelling of an elderly population: a self-reporting questionnaire survey. Dis Esophagus 24: 476-480, 2011. https://doi.org/10.1111/j.1442-2050.2011.01182.x 
10. Lim JH: Conservative treatment of dysphagia. Brain Neurorehabil 2: 108-112, 2009.

https://doi.org/10.12786/bn.2009.2.2.108

11. Kim SH: Comparative analysis of orofacial myofunctional in adults and eldery people. J Korea Acad-Ind Cooper Soc 20: 303-310, 2019. https://doi.org/10.5762/KAIS.2019.20.4.303

12. Bhoyar PS, Godbole SR, Thombare RU, Pakhan AJ: Effect of complete edentulism on masseter muscle thickness and changes after complete denture rehabilitation: an ultrasonographic study. J Investig Clin Dent 3: 45-50, 2012. https://doi.org/10.1111/j.2041-1626.2011.0088.x

13. Hara K, Tohara H, Kenichiro K, et al.: Association between tongue muscle strength and masticatory muscle strength. J Oral Rehabil 46: 134-139, 2019. https://doi:10.1111/joor.12737

14. Tamura F, Kikutani T, Tohara T, Yoshida M, Yaegaki K: Tongue thickness relates to nutritional status in the elderly. Dysphagia 27: 556-561, 2012. https://10.1007/s00455-012-9407-z

15. Müller F, Hernandez M, Grütter L, Aracil-Kessler L, Weingart D, Schimmel M: Masseter muscle thickness, chewing efficiency and bite force in edentulous patients with fixed and removable implant-supported prostheses: a cross-sectional multicenter study. Clin Oral Implants Res 23: 144-150, 2012. https://doi.org/10.1111/j.1600-0501.2011.02213.x

16. Van den Steen L, Schellen C, Verstraelen K, et al.: Tongue-strengthening exercises in healthy older adults: Specificity of bulb position and detraining effects. Dysphagia 33: 337-344. 2018. https://doi:10.1007/s00455-017-9858-3

17. Miura H, Kariyasu M, Sumi Y, Yamasaki K: [Labial closure force, activities of daily living, and cognitive function in frail elderly persons]. Nihon Ronen Igakkai Zasshi 45: 520-525, 2008. Japanese. https://doi.org/10.3143/geriatrics.45.520

18. Ibayashi H, Fujino Y, Pham TM, Matsuda S: Intervention study of exercise program for oral function in healthy elderly people. Tohoku J Exp Med 215: 237-245, 2008. https://doi.org/10.1620/tjem.215.237

19. Kim BJ, Ma SR: The effects of tongue pressure strength and accuracy training on tongue strength and speech function of chronic stroke patients. J Korea Contents Assoc 17: 156-166, 2017.

20. Jeon YJ, Choi JS, Han SJ: The effect of dry mouth improvement by oral exercise program in elderly people. J Korean Soc Dent Hyg 12: 293-305, 2012. https://doi.org/10.13065/jksdh.2012.12.2.293

21. Cho EP: Impact of oral function improving exercise on the oral function and quality of life in the elder. Unpublished doctoral dissertation, Chungnam National University, Daejeon, 2009.

22. Boljevic T, Vukcevic B, Pajic S, Pesic Z: Oral health-related quality of life of patients undergoing different treatment of facial fractures: the OHIP-14 questionnaire. Niger J Clin Pract 22: 1213-1217. 2019. https://doi.org/10.4103/njcp.njcp_124_19

23. Yang H, Han D, Ren $X$, Luo H, Li X: Investigation of swallowing function and swallowing-related quality of life after partial laryngectomy in Chinese patients with laryngeal carcinoma. Health Qual Life Outcomes 17: 132, 2019. https://doi.org/10.1186/s12955-019-1199-5

24. Statistics Korea: Korea Health Statistics: Korea National Health and Nutrition Examination Survey (KNHANES VI-2). Korea Center for Disease Control \& Prevention, Sejong, pp. 214-220, 2015.

25. Jang KA, Hwang IC: Effects of mouth excercise on the improvements of oral function in elderly men. J Dent Hyg Sci 11: 257-263, 2011.

26. Kim YJ, Choi YH, Kim JY, Lee HK: The effect of orophysical exercise for the elderly on oral function and nutrient intake. J Korean Acad Oral Health 35: 414-422, 2011.

27. Kim YS, Shin KH, Park JR, Chung SH, Choi HS: The effect of oral function improvement with oral exercise program by elderly people. J Korean Soc Dent Hyg 16: 559-566, 2016. https://doi.org/10.13065/jksdh.2016.16.04.559

28. Marshall TA, Warren JJ, Hand JS, Xie XJ, Stumbo PJ: Oral health, nutrient intake and dietary quality in the very old. $\mathrm{J}$ Am Dent Assoc 133: 1369-1379, 2002. https://doi.org/10.14219/jada.archive.2002.0052

29. Sagawa K, Furuya H, Ohara Y, et al.: Tongue function is important for masticatory performance in the healthy elderly: a cross-sectional survey of community-dwelling elderly. J Prosthodont Res 63: 31-34, 2019. https://doi.org/10.1016/j.jpor.2018.03.006

30. Takeuchi K, Aida J, Ito K, Furuta M, Yamashita Y, Osaka K: Nutritional status and dysphagia risk among community- 
dwelling frail older adults. J Nutr Health Aging 18: 352-357, 2014. https://doi.org/10.1007/s12603-014-0025-3

31. Kim MS, Park YH: The risk of dysphagia and dysphagiaspecific quality of life among community dwelling older adults in senior center. Korean J Adult Nurs 26: 393-402, 2014. https://doi.org/10.7475/kjan.2014.26.4.393

32. Hakuta C, Mori C, Ueno M, Shinada K, Kawaguchi Y:
Evaluation of an oral function promotion programme for the independent elderly in Japan. Gerodontology 26: 250-258. 2009. https://doi.org/10.1111/j.1741-2358.2008.00269.x

33. Lee SH, Ryu JA, Yu HE, Lee GH, Shin SJ: Comparison of effects according to type of oral exercise program for elderly in Gangneung city. J Dent Hyg Sci 16: 424-431, 2016. https://doi.org/10.17135/jdhs.2016.16.6.424 